\title{
Crossed Kirschner's wires for the treatment of anterior flail chest: an extracortical rib fixation
}

\author{
Felice Mucilli, Pierpaolo Camplese, Giuseppe Cipollone, Decio Di Nuzzo, Luigi Guetti, Marco Prioletta, \\ Mirko Barone*
}

Department of General and Thoracic Surgery, University Hospital "SS. Annunziata", Chieti, Italy

\author{
Received: 2 May 2016 \\ Accepted: 5 June 2016 \\ Published online: 29 August 2016 \\ *Corresponding author: Mirko \\ Barone, Department of General \\ and Thoracic Surgery, University \\ Hospital "SS. Annunziata”, Via \\ dei Vestini, 1,66100 Chieti $(\mathrm{CH})$, \\ Italy. Tell: +390871358289; Fax: \\ +390871358220; Email:mir87mb@ \\ libero.it
}

Competing interests: None.

Funding information: None.

Citation: Mucilli F, Camplese $P$, Cipollone G, Di Nuzzo D, Guetti L, Prioletta M, et al. Crossed Kirschner's wires for the treatment of anterior flail chest: an extracortical rib fixation. Journal of Emergency Practice and Trauma 2017; 3(1): 1117. doi: 10.15171/jept.2017.07

\begin{abstract}
Objective: Thoracic trauma may be a life-threatening condition. Flail chest is a severe chest injury with high mortality rates. Surgery is not frequently performed and, in Literature, data are controversial. The authors report their experience in the treatment of flail chest by an extracortical internal-external stabilization technique with Kirshner's wires (K-wires).

Methods: From 2010 to 2015, 137 trauma patients (109 males and 28 females) with an average age of $58.89 \pm 19.74$ years were observed. Seventeen (12.41\%) patients presented a flail chest and of these, 13 (9.49\%) with an anterior one. All flail chest patients underwent early chest wall surgical stabilization (within 48 hours from the injury).

Results: In the general population, an overall morbidity of $21.9 \%(n=30$ of 137$)$ and a 30-day mortality rate of $5.1 \%$ ( $n=7$ of 137 ) were observed. By clustering the population according to the treatment (medical or interventional vs surgical), significant statistically differences between the two cohorts were found in morbidity $(12.65 \%$ vs. $34.48 \%, P=0.002)$ and mortality rates $(1.28 \%$ vs. $10.34 \%, P=0.017)$. In patients undergoing chest wall surgical stabilization, with an average Injury Severity Score of $28.3 \pm 5.2$ and Abbreviated Injury Score (AIS) of $8.4 \pm 1.7$, an overall morbidity rate of $52.9 \%(n=9)$ and a mortality rate of $17.6 \%(n=3)$ were found. Post-surgical device removal, in local anesthesia or mild sedation, was performed $42.8 \pm 2.9$ days after chest wall stabilization and no cases of wound infection, dislodgment of the wires or osteosynthesis failure were reported. Moreover, in these patients, an early postoperative improvement in pulmonary ventilation $\left(\Delta \mathrm{paO}_{2}\right.$ and $\Delta \mathrm{pCO}_{2}:+9.49$ and -5.05 , respectively) was reported.

Conclusion: Surgical indication for the treatment of flail chest remains controversial and debated both due to an inadequate training and the absence of comparative prospective studies between various strategies. Our technique for the surgical treatment of the anterior flail chest seems to be anachronistic, but the aspects described, both in terms of technical features and of outcome and benefits (health, economic), allow to evaluate the effectiveness of this approach.

Keywords: Flail chest, Chest trauma, Kirschner's wire, Injury Severity Score, Abbreviated Injury Score.
\end{abstract}

\section{Introduction}

Thoracic trauma may be a life-threatening condition. In the United States and Europe, mortality rates in chest trauma patients amount up to $60 \%$. In addition, about a quarter of deaths in polytrauma patients can be attributed to thoracic injury (1). An operative treatment of blunt thoracic injury is required in less than $10 \%$ of cases; while in the majority of cases, medical therapy or interventional procedures (such as the placement of a chest drainage) are needed.

Flail chest is a severe chest injury with high mortality rates. In recent reports, it accounts for $9.1 \%$ (2) of thoracic traumas with a mortality rate of $20 \%-33 \%(3,4)$. Patients with severe chest injury can develop not only early dramatic consequences, but also long-term effects and disability. In addition, flail chest also presents local (respiratory impairment, shunt effect) and systemic (increased terminal complement components) pathophysiological effects causing catastrophic results (5). The use of positive pressure ventilation (PPV) has been described in these patients (6). However, this technique requires a prolonged mechanical ventilation which may arise in pulmonary complications (pulmonary infections, distress syndromes) with mortality rates up to $36 \%$ (7). Moreover, a conservative strategy does not always allow a stabilization of the bony stumps, resulting in osteosynthesis failures, debilitating chronic pain, secondary chest wall deformities up to $64 \%$ of cases (8). 
Surgery is not frequently performed and, in literature, data are controversial. It is reported that less than $2 \%$ of flail chests are surgically treated (2). The reasons of this underutilization have to be found in many causes, including unfamiliarity with the surgical technique and the lack of knowledge of the surgical indications for a prompt parietal stabilization (9). The operative treatment, on the other hand, is characterized by a reduction of mechanical ventilation, intensive care unit (ICU) stay, hospitalization, tracheostomy, mortality rates $(10,11)$ and only few reports report post-operative long-term complications $(12,13)$. But rib surgical stabilization is difficult both for the characteristics of the fractures (lack of uniformity and alignment) and for clinical conditions of trauma patients. Nowadays, many repair systems (cortical and intramedullary) are adopted in clinical practice. The authors report their experience in the treatment of flail chest by an extracortical internal-external stabilization technique with Kirshner's wires (K-wires).

\section{Methods}

From 2010 to 2015,137 trauma patients (109 males and 28 females) with an average age of $58.89 \pm 19.74$ years were observed in our department. Eighty-one (59.1\%) presented a chest trauma, while others had polytrauma (thoraco-abdominal, cranial-thoraco-abdominal). In almost all cases (n. 133 - 97.1\%), a blunt trauma was reported (e.g. direct trauma, precipitation) (Table 1 ).

On admission, all patients received a detailed clinical, laboratory (blood chemistry, arterial blood gases), cardiological (ECG, echocardiogram) and radiological assessment (total body CT, abdominal ultrasound), in order to evaluate clinical conditions and identify any early complications or undiagnosed injury. Moreover, all the urgent monitoring maneuvers (venous incannulation, bladder catheterization, saturation and cardiac rhythm monitoring) were set. The extent of trauma was stratified according to the Abbreviated Injury Scale (AIS) and the Injury Severity Score (ISS).

Thoracic cage injuries were observed in 113 patients (82.48\%) with an average of 3.2 fractured ribs per patient (mean 1.62 on the right and 1.75 on the left side). Sternal fractures $(24,17.5 \%)$, clavicle fractures $(19,13.9 \%)$ and vertebral ones $(15,10.9 \%)$ were also associated. Seventeen (12.41\%) patients presented a flail chest and of these, 13 (9.49\%) had an anterior one due to the presence of multiple rib fractures with or without a sternal one causing a paradoxical movement of the thorax. Considering the extent and the dynamics of impact, parietal traumas were associated with intrathoracic organ injuries such as pulmonary contusion $(61,44.5 \%)$, pulmonary laceration $(9$, $6.6 \%)$, pneumothorax $(46,33.6 \%)$, hemothorax, hemomediastinum or hemopericardium. Liver and spleen lacerations $(13,9.5 \%)$ and diaphragmatic rupture $(5,3.6 \%)$ were reported in thoraco-abdominal polytraumas.

Thirty-four patients (24.8\%) underwent urgency surgery (thoracic, abdominal or both), while the remainings were subjected to medical therapy $(79,57.7 \%)$ or to interven- tional procedures such as chest drain placement (24, 17.5\%) (Table 2).

All flail chest patients underwent early chest wall surgical stabilization (within 48 hours from the injury). In case of anterior paradoxical movement, we proceeded with an external-internal substernal surgical stabilization with crossed K-wires by anchoring them to healthy ribs immediately below or above those fractured. With the patient in the supine position, the technique involves a crossed placement (i.e. "Saint Andrew's cross") of these devices via a minimally invasive subxiphoid access or via a bilateral video thoracoscopic one (Figure 1). In open surgery, a subxiphoid incision is performed in order to access into the anterior mediastinum and to proceed with a blind-fingered dissection between the endothoracic fascia and the parietal pleurae. Protecting the pericardium with the back of the hand, K-wires are inserted laterally and beyond the fractured ribs with an oblique course and crossing them behind the sternum. The ends of these devices emerge to the skin in correspondence of the intercostal space immediately above or below the rib stumps. The access and the mediastinal digital dissection allow a rapid stabilization of the chest wall with the patient in bipulmonary ventilation and a chest drainage is usually not required. On the other hand, the minimally invasive bilateral thoracoscopic technique for anterolateral flail chests requires a single-lung ventilation and placement of a chest tube due to the access into the pleural cavity (Figure 2) as well as to drain an hemothorax or suturing lung lacerations.

\section{Results}

In the general population, an overall morbidity of $21.9 \%$ (30 of 137) and a 30 -day mortality rate of $5.1 \%$ (7 of 137) were observed. Anemia, respiratory failure and arrhythmias were the early most common complications. On admission, an average ISS of $15.60 \pm 10.76$ and an AIS of $5.80 \pm 3.12$ were calculated. The average hospital stay was $7.92 \pm 5.53$ days (Table 1 ).

By clustering the population according to the treatment (medical or interventional vs. surgical), in the first group the average hospital stay was $5.47 \pm 4.33$, while in the second it was $11.26 \pm 5.25(P<0.001)$. Moreover, significant statistically differences between the two cohorts in morbidity $(12.65 \%$ vs. $34.48 \%, P=0.002)$ and mortality rates ( $1.28 \%$ vs. $10.34 \%, P=0.017$ ) were found (Table 3 ). In particular, regarding the patients undergoing chest wall surgical stabilization $(n=17)$, the frequencies appear higher; in fact, an overall morbidity rate of $52.9 \%(n=9)$, mostly attributable to anemia and post-operative respiratory failure (Clavien-Dindo score $=3$ ), and a mortality one of $17.6 \%(n=3)$ were noted. This can be explained considering patient's clinical conditions and the early respiratory and metabolic effects that develop in flail chest patients, rather than the surgical technique itself. In fact, the average ISS was $28.3 \pm 5.2$ with an AIS of $8.4 \pm 1.7$. Post-surgical device removal, in local anesthesia or mild sedation, was performed $42.8 \pm 2.9$ days after chest wall stabiliza- 
Table 1. General population characteristics

\begin{tabular}{|c|c|c|c|c|}
\hline Variable & No. & Average & $\%$ & \\
\hline \multicolumn{5}{|l|}{ Sex } \\
\hline Male & 109 & & 79.6 & \\
\hline Female & 28 & & 20.4 & \\
\hline Age & & $58.89 \pm 19.74$ & & $(16.00-98.00)$ \\
\hline \multicolumn{5}{|l|}{ Kind of trauma } \\
\hline Blunt & 133 & & 97.1 & \\
\hline Open & 4 & & 2.9 & \\
\hline \multicolumn{5}{|l|}{ Type of trauma } \\
\hline Thoracic & 81 & & 59.1 & \\
\hline Thoraco-abdominal & 34 & & 24.8 & \\
\hline Head-thoracic & 14 & & 10.2 & \\
\hline Head-thoracic-abdominal & 8 & & 5.8 & \\
\hline AIS & & $5.8 \pm 3.12$ & & $(2.00-12.00)$ \\
\hline ISS & & $15.6 \pm 10.76$ & & $(4.00-50.0)$ \\
\hline \multicolumn{5}{|l|}{ Treatment } \\
\hline Medical & 79 & & 57.7 & \\
\hline Surgical & 34 & & 24.8 & \\
\hline Interventional & 24 & & 17.5 & \\
\hline Hospital stay & & $7.92 \pm 5.53$ & & $(2.00-33.00)$ \\
\hline Morbidity & 30 & & 21.9 & $\begin{array}{l}n=11 \text { Anemia } \\
n=7 \text { Respiratory failure } \\
n=4 \text { Pneumonia } \\
n=2 \text { Myocardial infarction } \\
n=2 \text { Sepsis } \\
n=2 \text { Renal Failure } \\
n=1 \text { Ventricular fibrillation } \\
n=1 \text { Atrial fibrillation }\end{array}$ \\
\hline
\end{tabular}

Abbreviations: AIS, Abbreviated Injury Scale; ISS, Injury Severity Score.

Table 2. Trauma characteristics

\begin{tabular}{lcc}
\hline & No. of patients & $\%$ \\
\hline Thoracic cage injuries & 113 & \\
Rib fractures & 24 & 82.48 \\
Sternal fractures & 19 & 17.5 \\
Clavicle fractures & 15 & 13.9 \\
Vertebral fractures & 3 & 10.9 \\
Scapular fractures & 17 & 2.2 \\
Flail chest & & 12.14 \\
Intrathoracic organ injuries & & \\
Pulmonary contusion & 61 & 44.5 \\
Lung laceration & 9 & 6.6 \\
Great vessels injury & 4 & 2.9 \\
Pneumothorax & 46 & 33.6 \\
Hemothorax & 28 & 20.4 \\
Hemopericardium & 7 & 5.1 \\
Diaphragmatic injury & 5 & 3.6 \\
Intraabdominal organ injuries & & \\
Hepatic contusion/laceration & 4 & 2.9 \\
Spleen laceration & 9 & 6.6 \\
Intestinal laceration & 1 & 0.7 \\
Kidney injury & 4 & 2.9 \\
\hline H & & \\
\hline
\end{tabular}

${ }^{a} \mathrm{n}=13$ anterior; $\mathrm{n}=4$ antero-lateral.

tion and no cases of wound infection, dislodgment of the wires or osteosynthesis failure were reported. Cumulative reoperation rate was $0.0 \%$ (Table 4 ).

In the second part of the study, a descriptive analysis of changes in respiratory $\left(\mathrm{paO}_{2}, \mathrm{pCO}_{2}, \mathrm{SaO}_{2}\right)$ and metabolic parameters ( $\mathrm{pH}$, lactate, glucose), derived from pre-operative and post-operative (third P.O.D.) arterial blood gas analyses, was performed in K-wire patients. Data shows surgery correlates with an early improvement in pulmonary ventilation $\left(\Delta \mathrm{paO}_{2}\right.$ and $\Delta \mathrm{pCO}_{2}:+9.49 \mathrm{~mm} \mathrm{Hg}$ and $-5.05 \mathrm{~mm} \mathrm{Hg}$, respectively) (Figure 3 ). Moreover, the bivariate analysis demonstrates that postoperative complications correlate with the count of postoperative blood gas metabolites rather than the preoperative ones; in other words, an early poor adaptation and a lack of improvement of the aforesaid parameters are predictors of postoperative morbidity (Table 5).

\section{Discussion}

With the advent of the internal pneumatic stabilization and the early report by Avery et al (14) in 1956, the management of chest trauma veered towards non-operative treatments, although since from the outset the relatedcomplications were clear (15). Today, a renewed interest in surgical stabilization techniques occurs. In 2002, Tanaka et al (16) reported the benefits of surgery for flail chest treatment. Although these results are encouraging, but surgical stabilization of the flail chest remains an underutilized procedure due to multiple factors, such as unfamiliarity and lack of knowledge of surgical indications $(7,9,17)$. Moreover, surgical indication for the treatment of flail chest remains subject of extensive debate. Lardinois et al (18) reported 66 patients with anterolateral flail chest 


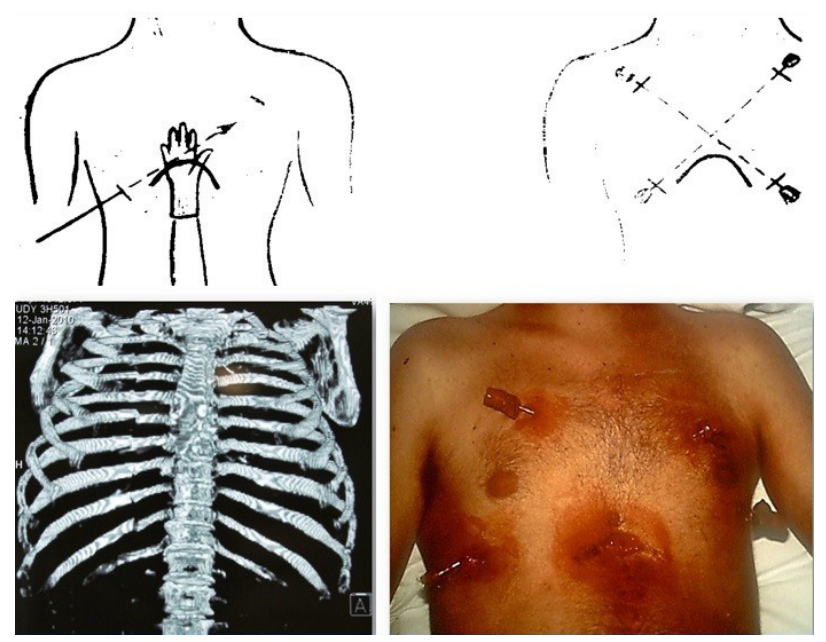

Figure 1. Surgical technique for the stabilization of the anterior flail chest with crossed Kirschner's wires (subxiphoid access).

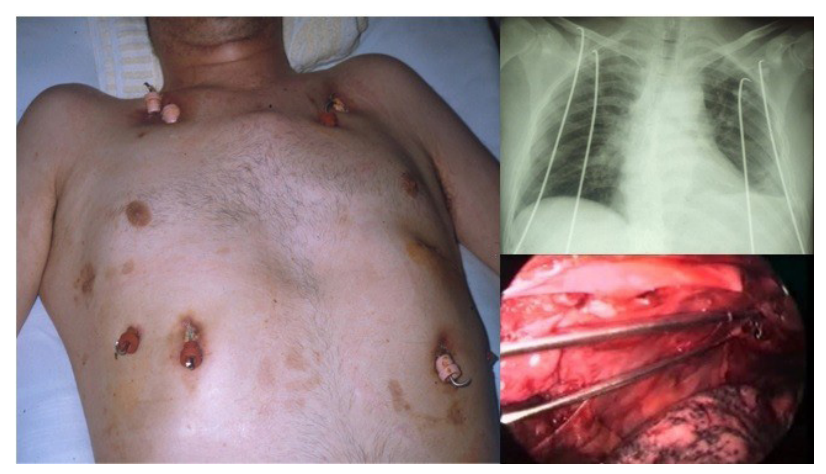

Figure 2. Surgical technique for the stabilization of the anterior flail chest with crossed Kirschner's wires (videothoracoscopic access).

who underwent $3.5 \mathrm{~mm}$-plate surgical stabilization. The authors posed surgical indication in non-intubated patients with refractory respiratory failure, in patients with flail chest disalignment, in intubated patients without severe pulmonary contusion or brain injuries who did not require prolonged intubation and in patients requiring an emergency thoracotomy due to the presence of intrathoracic organ injury.

In the 2013 Eastern Association for the Surgery of Trauma guidelines (5), the only two indications for surgical fixation are the respiratory decline of a flail chest patient failing to wean from the ventilator and the need to perform a thoracotomy regardless the presence of a flail chest.

But, the same guidelines recommend that an early prophylactic chest stabilization should be avoided because it does not show any benefit. Moreover, the presence of ex- tensive pulmonary contusion is a relative contraindication for surgery, as these patients require prolonged mechanical ventilation (19).

However, at the worsening of patient's ventilation or at the partial resolution of contusions, surgical stabilization can be envisaged (20); while, in patients with severe isolated parietal injury, an early surgical fixation (within 72 hours) can reduce the risk of potential ventilator-related infectious complications, ICU stay and can prevent the onset of post-traumatic restrictive pulmonary syndromes. Another indication for surgical stabilization is the extension and location of the flail chest. In fact, in young patients in case of an extended anterolateral flail chest, surgery is immediately indicated, even in the absence of respiratory complications, due to the high risk of dislocation of the rib stumps. Posterior parietal defects are rarely surgically treated, except for the presence of wedging fractured lines within the pleural cavity that may lacerate intrathoracic organs. Moreover, respiratory dynamics is ensured by the bony structures of the shoulder girdle and the action of the trapezius, serratus and latissimus dorsi.

In our experience, we take into account for surgical stabilization the extent of the flail chest, the onset of respiratory failure or muscle fatigue and the presence of a concomitant indication for urgency surgery for other reasons. We also believe that a wait and see strategy could increase the risk of morbidity and mortality. Moreover, older patients ( $>70$ years) do not have negligible comorbidity (i.e. COPD, pulmonary emphysema) and need early surgical chest stabilization avoiding serious deterioration of their clinical conditions. Therefore, the early changes of respiratory parameters pose surgical indication, except for the presence of severe organ injury (brain, diffuse pulmonary contusions).

In literature, many surgical fixation techniques are reported with several devices that can be divided into: devices for cortical stabilization (cerclage wires and clamping, screw fixation ones) and those for intramedullary stabilization (K-wires, Rehbein plate, rib splints) (17).

The rationale is the mechanical function restoration of the chest wall. Among the cerclage techniques, historically, Paris et al (21) introduced a $40 \mathrm{~cm}$-length temporary struts with four or five holes to anchor to the cortex of fractured ribs.

The experiences by Judet (22) and by Sanches-Lloret et al (23) are just historical notes. The modern evolution of cortical fixation for fractured ribs has led to the development of anatomically shaped plates - U-plate (24), ana-

Table 3. Independent samples t test (medical and interventional/surgical treatment vs outcome)

\begin{tabular}{|c|c|c|c|c|c|c|c|c|}
\hline & & \multirow{2}{*}{$\mathbf{N}$} & \multirow{2}{*}{$\%$} & \multirow{2}{*}{ Average } & \multirow{2}{*}{$\mathrm{SD}(\Delta)$} & \multicolumn{2}{|c|}{$95 \% \mathrm{Cl}$} & \multirow{2}{*}{$P(\chi 2)$} \\
\hline & & & & & & Min & Max & \\
\hline \multirow{2}{*}{ Hospital stay (days) } & Medical & $79 / 137$ & 57.66 & 5.47 & 4.33 & -7.412 & -4.168 & 0.000 \\
\hline & Interventional/Surgical & $58 / 137$ & 42.34 & 11.26 & 5.42 & -8.64 & -4.43 & \\
\hline \multirow{2}{*}{ Morbidity rate (\%) } & Medical & $10 / 79$ & 12.65 & & & & & \\
\hline & Interventional/Surgical & $20 / 58$ & 34.48 & & & & & 0.002 \\
\hline \multirow{2}{*}{ Mortality rate (\%) } & Medical & $1 / 78$ & 1.28 & & & & & \\
\hline & Interventional/Surgical & $6 / 58$ & 10.34 & & & & & 0.017 \\
\hline
\end{tabular}


Table 4. Clinical finding and post-operative outcome in flail chest patients undergoing surgical stabilization

\begin{tabular}{lcccc}
\hline & $\mathbf{N}$ & Average & $\%$ & \\
\hline Flail chest patients & 17 & & & $\begin{array}{c}\text { n }=13 \text { anterior } \\
\mathrm{n}=4 \text { lateral }\end{array}$ \\
Morbidity & $9 / 17$ & & 52.9 & \\
Mortality & $3 / 17$ & & 17.6 & \\
ISS & & $28.3 \pm 5.2$ & & \\
AIS & & $8.4 \pm 1.7$ & & \\
Post-surgical device & & $42.8 \pm 2.9$ & & \\
removal (days) & & & 0 & \\
Reoperation rate & 0 & &
\end{tabular}

tomical rib plates $(3,25,26)$. Nowadays, these latters can also be fixed via a minimally invasive technique (minimally invasive plate osteosynthesis or MIPO) (27).

Intramedullary implants have also been described. Kwires have been reported in numerous reports with good results, although cases of rotatory instability (28) or dislocation (29) have been described. In this regard, preformed rib splints (30) have been introduced for fracture fixation ensuring both radial and rotational stability; in addition, they do not present risks of migration $(31,32)$ as an extremity is fixed to the proximal portion of the fractured rib. Finally, an emerging concept for treatment of rib fractures is the use of bioabsorbable materials (33). Finally, Liović et al (34) have reported a new experimental technique using an intramedullary telescoping splint anchored by bone cement.

Our proposed technique for the treatment of the anterior flail chest may appear anachronistic, but the procedure presents some peculiarities that should be considered in

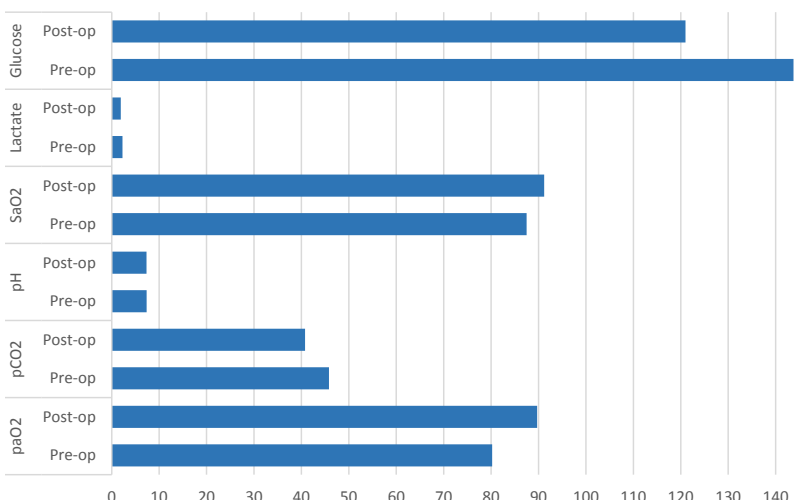

Figure 3. Early postoperative changes in respiratory and metabolic parameters in flail chest patients.

case of a polytrauma patient.

First of all, it is of rapid execution and, in the subxiphoid technique, it does not require a pleural drainage. The patient is placed in the supine position, therefore, limiting any movements or tractions on the spine and the organs. Finally, we did not record any procedure-related complication (rejections, infections, decubitus) or osteosynthesis failure. The insertion of a $8 \mathrm{~mm}-\mathrm{K}$-wire can be safely performed both in open technique (the device flows between the operator's hand and the endothoracic fascia) and in the video assisted one. The removal is typically 40 days after the surgery under local anesthesia or mild sedation. The result is the absence of foreign bodies or permanent implants in the chest. Moreover, it is also economical when compared to the costs of intramedullary fixation (ORIF); in fact, for the latter the amount is from $\$ 15000$

Table 5. Blood gas analysis vs post-operative complications

\begin{tabular}{|c|c|c|c|c|c|c|c|c|c|}
\hline & & \multirow{2}{*}{$\mathbf{N}$} & \multirow{2}{*}{ Average } & \multirow{2}{*}{ SD } & & \multirow{2}{*}{$\begin{array}{c}\Delta \\
\text { (post-pre) }\end{array}$} & \multicolumn{2}{|c|}{$95 \% \mathrm{Cl}$} & \multirow{2}{*}{ P (vs complications) } \\
\hline & & & & & & & Min & Max & \\
\hline \multirow{4}{*}{$\begin{array}{l}\mathrm{paO} 2 \\
(\mathrm{~mm} \mathrm{Hg})\end{array}$} & Preoperative & 17 & 80.22 & 8.81 & $(56.10-91.30)$ & +9.49 & & & 0.908 \\
\hline & Postoperative & 17 & 89.71 & 7.01 & $(75.00-96.90)$ & & & & 0.088 \\
\hline & Complications & 9 & 80.44 & 4.93 & & & -8.296 & 9.260 & \\
\hline & No Complications & 8 & 82.23 & 11.97 & & & -12.579 & 0.985 & \\
\hline \multirow{4}{*}{$\begin{array}{l}\text { pCO2 } \\
(\mathrm{mm} \mathrm{Hg})\end{array}$} & Preoperative & 17 & 45.81 & 7.61 & $(29.90-59.90)$ & -5.05 & & & 0.168 \\
\hline & Postoperative & 17 & 40.76 & 9.06 & $(29.90-45.80)$ & & & & 0.006 \\
\hline & Complications & 9 & 48.24 & 6.77 & & & -2.442 & 12.806 & \\
\hline & No Complications & 8 & 43.06 & 7.98 & & & 4.097 & 20.444 & \\
\hline \multirow{4}{*}{$\begin{array}{l}\mathrm{SaO} 2 \\
(\%)\end{array}$} & Preoperative & 17 & 87.49 & 3.24 & $(78.90-92.00)$ & +3.69 & & & 0.581 \\
\hline & Postoperative & 17 & 91.18 & 5.60 & $(82.20-94.20)$ & & & & 0.011 \\
\hline & Complications & 9 & 87.49 & 3.24 & & & -4.341 & 2.524 & \\
\hline & No Complications & 8 & 87.73 & 4.24 & & & -8.855 & -1.364 & \\
\hline \multirow{4}{*}{$\mathrm{pH}$} & Preoperative & 17 & 7.35 & 0.04 & $(7.28-7.45)$ & -0.01 & & & 0.075 \\
\hline & Postoperative & 17 & 7.34 & 0.06 & (7.27-7.48) & & & & 0.002 \\
\hline & Complications & 9 & 7.33 & 0.03 & & & -0.091 & 0.005 & \\
\hline & No Complications & 8 & 7.37 & 0.06 & & & -0.137 & -0.036 & \\
\hline \multirow{4}{*}{$\begin{array}{l}\text { Lactate } \\
(\mathrm{mg} / \mathrm{dL})\end{array}$} & Preoperative & 17 & 2.28 & 1.24 & $(1,00-5.70)$ & -0.36 & & & 0.244 \\
\hline & Postoperative & 17 & 1.92 & 1.54 & $(0.60-4.10)$ & & & & 0.042 \\
\hline & Complications & 9 & 2.28 & 1.24 & & & -0.546 & 1.991 & \\
\hline & No Complications & 8 & 1.92 & 1.12 & & & 0.04372 & 2.130 & \\
\hline \multirow{4}{*}{$\begin{array}{l}\text { Glucose } \\
\text { (mg/dL) }\end{array}$} & Preoperative & 17 & 143.76 & 42.69 & $(93.00-254.00)$ & -22.76 & & & 0.076 \\
\hline & Postoperative & 17 & 121.00 & 39.11 & $(80.00-225.00)$ & & & & 0.005 \\
\hline & Complications & 9 & 2.28 & 1.24 & & & -4.353 & 77.603 & \\
\hline & No Complications & 8 & 1.92 & 1.12 & & & 22.115 & 82.718 & \\
\hline
\end{tabular}


to $\$ 30000(35,31)$.

Postoperative complication rate was $52.9 \%(n=9$ of 17$)$ but none related with surgery, except 2 cases of acute respiratory failure. In one of these, subjected to emergency stabilization for an extended iatrogenic flail chest by an external cardiac massage, the etiology referred to a diffuse parenchymal injury. In the flail chest study arm, we observed a $17.6 \%$ mortality rate $(n=3$ of 17$)$, a slightly lower occurrence than to those reported in the literature (34). Extracortical surgical chest wall stabilization with $\mathrm{K}$-wires results in an early improvement of the respiratory parameters. As reported, in our experience we noticed a significant improvement in arterial blood gas parameters from the third post-operative day $\left(\Delta \mathrm{paO}_{2}\right.$ and $\Delta \mathrm{pCO}_{2}:+9.49$ and -5.05 , respectively) and the bivariate analysis demonstrated the complication rate correlates with the count of postoperative blood gas metabolites rather than the preoperative ones; in other words, an early poor adaptation and a lack of improvement of the aforesaid parameters are predictors of postoperative morbidity.

\section{Conclusion}

Although these encouraging results, surgical indication for the treatment of flail chest remains controversial and debated due to both an inadequate training and the absence of comparative prospective studies between various strategies. Nowadays, a gold standard technique is not still present, resulting in a widespread fragmentation of experiences and results. Our technique for the surgical treatment of the anterior flail chest seems to be anachronistic in an era of strong technological innovations. Despite this, the aspects described, both in terms of technical features and of outcome and benefits (health, economic), allow to evaluate the effectiveness of this approach.

\section{Ethical issues}

The article does not contain any research with human participants performed by the authors. For this type of study, no formal consent is required. It is an anonymous one.

\section{Authors' contributions}

All authors participated in data collection, statistical analysis and text writing.

\section{References}

1. Clark GC, Schecter WP, Trunkey DD. Variables affecting outcome in blunt chest trauma: flail chest vs. pulmonary contusion. J Trauma 1988; 28(3): 298-304. doi: 10.1097/00005373-198803000-00004.

2. Cannon RM, Smith JW, Franklin GA, Harbrecht BG, Miller FB, Richardson JD. Flail chest injury: are we making any progress? Am Surg 2012; 78(4): 398-402.

3. Jayle CP, Allain G, Ingrand P, Laksiri L, Bonnin E, HajjChahine J, et al. Flail chest in polytraumatized patients: surgical fixation using Stracos reduces ventilator time and hospital stay. Biomed Res Int 2015; 2015: 624723. doi: 10.1155/2015/624723.

4. Fowler TT, Taylor BC, Bellino MJ, Althausen PL. Surgical treatment of flail chest and rib fractures. J Am Acad Orthop
Surg 2014; 22(12): 751-60. doi: 10.5435/JAAOS-22-12-751.

5. Simon B, Ebert J, Bokhari F, Capella J, Emhoff T, Hayward $\mathrm{T}$ 3rd, et al. Management of pulmonary contusion and flail chest: an Eastern Association for the Surgery of Trauma practice management guideline. J Trauma Acute Care Surg 2012; 73(5 Suppl 4): S351-61. doi: 10.1097/ TA.0b013e31827019fd.

6. Gunduz $\mathrm{M}$, Unlugenc $\mathrm{H}$, Ozalevli $\mathrm{M}$, Inanoglu $\mathrm{K}$, Akman H. A comparative study of continuous positive airway pressure (CPAP) and intermittent positive pressure ventilation (IPPV) in patients with flail chest. Emerg Med J 2005; 22(5): 325-9. doi: 10.1136/emj.2004.019786.

7. Richardson JD, Franklin GA, Heffley S, Seligson D. Operative fixation of chest wall fractures: an underused procedure? Am Surg 2007; 73(6): 591-6.

8. Landercasper J, Cogbill TH, Lindesmith LA. Long-term disability after flail chest injury. J Trauma 1984; 24(5): 4104.

9. Mayberry JC, Ham LB, Schipper PH, Ellis TJ, Mullins RJ. Surveyed opinion of American trauma, orthopedic, and thoracic surgeons on rib and sternal fracture repair. J Trauma 2009; 66(3): 875-9. doi: 10.1097/TA.0b013e318190c3d3.

10. Cataneo AJ, Cataneo DC, de Oliveira FH, Arruda KA, El Dib R, de Oliveira Carvalho PE. Surgical versus nonsurgical interventions for flail chest. Cochrane Database Syst Rev 2015; (7): CD009919. doi: 10.1002/14651858.CD009919. pub2.

11. Leinicke JA, Elmore L, Freeman BD, Colditz GA. Operative management of rib fractures in the setting of flail chest: a systematic review and meta-analysis. Ann Surg 2013; 258(6): 914-21. doi: 10.1097/SLA.0b013e3182895bb0.

12. Nirula R, Allen B, Layman R, Falimirski ME, Somberg LB, Rib fracture stabilization in patients sustaining blunt chest injury. Am Surg 2006; 72(4): 307-9.

13. Mayberry JC, Kroeker AD, Ham LB, Mullins RJ, Trunkey DD. Long-term morbidity, pain, and disability after repair of severe chest wall injuries. Am Surg 2009; 75(5): 389-94.

14. Avery EE, Benson DW, Morch ET. Critically crushed chests; a new method of treatment with continuous mechanical hyperventilation to produce alkalotic apnea and internal pneumatic stabilization. J Thorac Surg 1956; 32(3): 291-311.

15. Ginsberg RJ, Kostin RF. New approaches to the management of flail chest. Can Med Assoc J 1977; 116(6): 613-5.

16. Tanaka H, Yukioka T, Yamaguti Y, Shimizu S, Goto $\mathrm{H}$, Matsuda $\mathrm{H}$, et al. Surgical stabilization of internal pneumatic stabilization? A prospective randomized study of management of severe flail chest patients. J Trauma 2002; 52(4): 727-32.

17. Fitzpatrick DC, Denard PJ, Phelan D, Long WB, Madey SM, Bottlang M. Operative stabilization of flail chest injuries: review of literature and fixation options. Eur J Trauma Emerg Surg 2010; 36(5): 427-33. doi: 10.1007/s00068-0100027-8.

18. Lardinois D, Krueger T, Dusmet M, Ghisletta N, Gugger $\mathrm{M}$, Ris HB. Pulmonary function testing after operative stabilisation of the chest wall for flail chest. Eur J Cardiothorac Surg 2001; 20(3): 496-501.

19. Richardson JD, Adams L Flint LM. Selective management of flail chest and pulmonary contusion. Ann Surg 1982; 196(4): 481-7. doi: 10.1097/00000658-198210000-00012.

20. Tzelepis GE, McCool FD, Hoppin FG Jr. Chest wall distortion in patients with flail chest. Am Rev Respir Dis 1989; 140(1): 31-7. doi: 10.1164/ajrccm/140.1.31. 
21. Paris F, Tarazona V, Blasco E, Canto A, Casillas M, Pastor J, et al. Surgical stabilization of traumatic flail chest. Thorax 1975; 30(5): 521-7. doi: 10.1136/thx.30.5.521.

22. Judet R. Osteosynthese costale. Rev Chir Orthop Reparatrice Appar Mot 1973; 59(Suppl 1): 334-5. [in French].

23. Sanchez-Lloret J, Letang E, Mateu M, Callejas MA, Catalan $\mathrm{M}$, Canalis $\mathrm{E}$, et al. Indications and surgical treatment of the traumatic flail chest syndrome. An original technique. Thorac Cardiovasc Surg 1982; 30(5): 294-7. doi: 10.1055/s2007-1022410.

24. Sales JR, Ellis TJ, Gillard J, Liu Q, Chen JC, Ham B, et al. Biomechanical testing of a novel, minimally invasive rib fracture plating system. J Trauma 2008; 64(5): 1270-4. doi: 10.1097/TA.0b013e31804a7fd5.

25. Ramponi F, Meredith GT, Bendinelli C, Söderlund T. Operative management of flail chest with anatomical locking plates (MatrixRib). ANZ J Surg 2012;82(9):658-9. doi: 10.1111/j.1445-2197.2012.06159.x.

26. Bottlang M, Walleser S, Noll M, Honold S, Madey SM, Fitzpatrick D, et al. Biomechanical rationale and evaluation of an implant system for rib fracture fixation. Eur J Trauma Emerg Surg 2010;36(5):417-26. doi: 10.1007/s00068-0100047-4.

27. Bemelman M, van Baal M, Yuan JZ, Leenen L. The role of minimally invasive plate osteosynthesis in rib fixation: a review. Korean J Thorac Cardiovasc Surg 2016; 49(1): 1-8. doi: 10.5090/kjtcs.2016.49.1.1.

28. Engel C, Krieg JC, Madey SM, Long WB, Bottlang M.
Operative chest wall fixation with osteosynthesis plates. J Trauma 2005; 58(1): 181-6.

29. Shah TJ. On internal fixation for flail chest. J Thorac Cardiovasc Surg 1996; 112(3): 849-50.

30. Helzel I, Long W, Fitzpatrick D, Madey S, Bottlang M. Evaluation of intramedullary rib splints for less-invasive stabilisation of rib fractures. Injury 2009; 40(10): 1104-10. doi: 10.1016/j.injury.2009.06.004.

31. Granhed HP, Pazooki D. A feasibility study of 60 consecutive patients operated for unstable thoracic cage. J Trauma Manag Outcomes 2014; 8(1): 20. doi: 10.1186/ s13032-014-0020-z.

32. Marasco SF, Davies AR, Cooper J, Varma D, Bennett V, Nevill $\mathrm{R}$, et al. Prospective randomized controlled trial of operative rib fixation in traumatic flail chest. J Am Coll Surg 2013; 216(5): 924-32. doi: 10.1016/j.jamcollsurg.2012.12.024.

33. Nolasco-de la Rosa AL, Mosiñoz-Montes R, MatehualaGarcía J, Román-Guzmán E, Quero-Sandoval F, ReyesMiranda AL. Unstable thorax fixation with bioabsorbable plates and screws. Presentation of some cases. Cir Cir 2015; 83(1): 23-8. doi: 10.1016/j.circir.2015.04.019. [in Spanish]

34. Liovic P, Šutalo ID, Marasco SF. Fixation of a human rib by an intramedullary telescoping splint anchored by bone cement. Comput Methods Biomech Biomed Engin 2016; 19(12): 1297-305. doi: 10.1080/10255842.2015.1131979.

35. Bhatnagar A, Mayberry J, Nirula R. Rib fracture fixation for flail chest: what is the benefit? J Am Coll Surg 2012; 215(2): 201-5. doi: 10.1016/j.jamcollsurg.2012.02.023. 